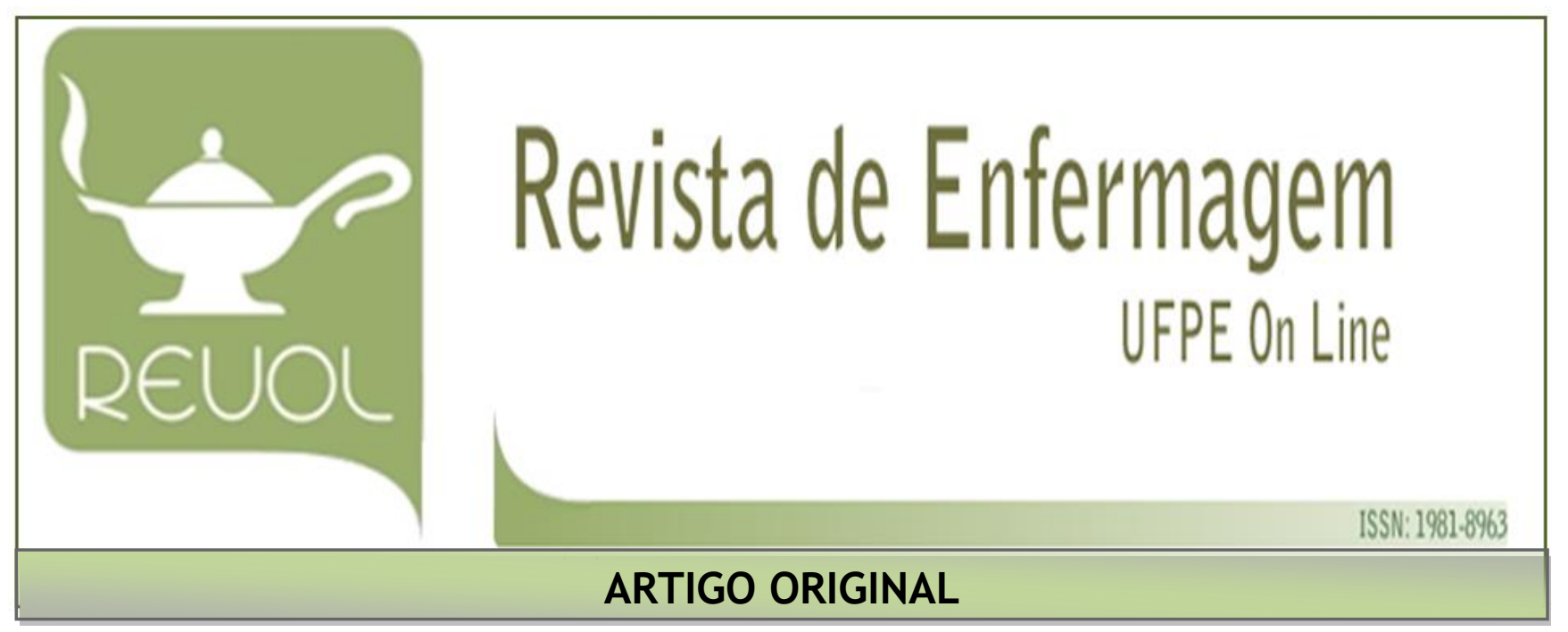

\title{
PERSPECTIVA DE PROFISSIONAIS DE ENFERMAGEM SOBRE A MORTE NA EMERGÊNCIA
}

\section{PERSPECTIVE OF NURSING PROFESSIONALS ON DEATH IN THE EMERGENCY PERSPECTIVA DE PROFESIONALES DE ENFERMERÍA SOBRE LA MUERTE EN LA EMERGENCIA}

Ana Elisa Baldissera ${ }^{1}$, Luana Cristina Bellini' ${ }^{2}$, Ana Lucia Mendes Ferrer ${ }^{3}$, Mayckel da Silva Barreto ${ }^{4}$, Jorseli Angela Henriques Coimbra ${ }^{5}$, Sonia Silva Marcon ${ }^{6}$

\begin{abstract}
RESUMO
Objetivo: conhecer a perspectiva dos profissionais de Enfermagem, que atuam na sala de emergência, sobre o processo de morte e morrer. Método: estudo qualitativo, descritivo e exploratório, realizado com 17 profissionais de Enfermagem que atuavam na sala de emergência de um hospital universitário. Os dados foram coletados por meio de entrevistas semiestruturadas, audiogravadas que, após transcritas, foram submetidas à Análise de Conteúdo na modalidade Temática. Resultados: emergiram as categorias - Sentimentos e percepções frente ao processo de morte e morrer e Alterações na percepção da morte em diferentes fases da vida. Ambas mostram sentimentos, experiências iniciais com a morte enquanto profissional e a falta de preparo acerca do tema durante a formação. Conclusão: os profissionais entendem que a morte faz parte do processo de viver, mas sentem tristeza, frustração e impotência, especialmente, quando o paciente permanece por mais tempo na emergência. Acredita-se que este estudo possa contribuir para que os profissionais se sintam motivados para refletir e discutir sobre cuidados mais humanos e solidários no serviço hospitalar de urgência. Descritores: Morte; Profissionais de Enfermagem; Serviços Médicos de Emergência; Serviço Hospitalar de Emergência; Percepção; Relações Profissional-Paciente.

\section{ABSTRACT}

Objective: to know the perspective of Nursing professionals, who work in the emergency room, about the process of death and dying. Method: a qualitative, descriptive and exploratory study, carried out with 17 Nursing professionals who worked in the emergency room of a university hospital. Data was collected through semi-structured, audio-taped interviews that, after being transcribed, were submitted to Content Analysis in the Thematic modality. Results: categories emerged - Feelings and perceptions regarding the process of death and dying and Alterations in the perception of death in different phases of life. Both show feelings, initial experiences with death as a professional, and lack of preparation on the subject during training. Conclusion: professionals understand that death is part of the process of living, but they feel sadness, frustration and impotence, especially when the patient stays for longer in the emergency room. It is believed that this study may contribute to the professionals feel motivated to reflect and discuss more humane and supportive care in the hospital emergency service. Descriptors: Death; Nurse Practitioners; Emergency Medical Services; Emergency Service Hospital; Perception; Professional-Patient Relations.
\end{abstract}

\section{RESUMEN}

Objetivo: conocer la perspectiva de los profesionales de Enfermería, que actúan en la sala de emergencia, sobre el proceso de muerte y morir. Método: estudio cualitativo, descriptivo y exploratorio, realizado con 17 profesionales de Enfermería que actuaban en la sala de emergencia de un hospital universitario. Los datos fueron recolectados por medio de entrevistas semiestructuradas, audiogravadas que, tras transcritas, fueron sometidas al Análisis de Contenido, en la modalidad Temática. Resultados: surgieron dos categorías Sentimientos y percepciones frente al proceso de muerte y morir y Alteraciones en la percepción de la muerte en diferentes fases de la vida. Ambos muestran sentimientos, experiencias iniciales con la muerte como profesional y la falta de preparación acerca del tema durante la formación. Conclusión: los profesionales entienden que la muerte es parte del proceso de vivir, pero sienten tristeza, frustración e impotencia, especialmente cuando el paciente permanece por más tiempo en la emergencia. Se cree que este estudio puede contribuir a que los profesionales, se sientan motivados para reflexionar y discutir sobre cuidados más humanos y solidarios en el servicio hospitalario de urgencia. Descriptores: Muerte; Enfermeras Practicantes; Servicios Médicos de Urgencia; Servicio de Urgencia en Hospital; Percepción; Relaciones Profesional-Paciente.

${ }^{1}$ Enfermeira, Universidade Estadual de Maringá/UEM. Maringá (PR), Brasil. E-mail: analisa_baldissera@hotmail.com ORCID iD: http://orcid.org/0000-0003-3693-1029; ${ }^{2}$ Mestranda, Programa de Mestrado em Enfermagem, Universidade Estadual de Maringá/UEM. Maringá (PR), Brasil. E-mail: luana.bellini@hotmail.com ORCID iD: http://orcid.org/0000-0001-8460-1177; ${ }^{3}$ Mestra, Hospital Universitário de Maringá/HUM. Maringá (PR), Brasil. E-mail: analuferrer@hotmail.com. ORCID iD: http://orcid.org/0000-0001-8606-1194; ${ }^{4}$ Doutor, Faculdade de Filosofia, Ciências e Letras de Mandaguari/FAFIMAN. Mandaguari (PR), Brasil. E-mail: mayckelbar@gmail.com ORCID iD: http://orcid.org/0000-0003-2290-8418; ${ }^{5}$ Doutora, Universidade Estadual de Maringá/UEM. Maringá (PR), Brasil. E-mail: jahcoimbra@uem.br ORCID iD: http://orcid.org/0000-0002-9314-9175; ' ${ }^{6}$ Doutora, Universidade Estadual de Maringá/UEM. Maringá (PR), Brasil. E-mail: soniasilva.marcon@gmail.com ORCID iD: http://orcid.org/0000-0002-6607-362X 


\section{INTRODUÇÃO}

Faz parte do ciclo natural da vida o processo de morte e morrer, embora visto pela sociedade contemporânea como um acontecimento que vai em sentido contrário, marcado por sentimentos de pesar, impotência e frustração, principalmente, por envolver a não aceitação da perda e dificuldades de enfrentá-la. ${ }^{1}$

Existem vários significados e conceitos sobre a morte que envolvem aspectos biológicos, religiosos, materiais e culturais. Pode-se entender a morte de forma simplista como a junção de fatores biológicos e patológicos decorrente da falha de algum órgão vital por meio de acidentes, doenças agudas ou crônicas degenerativas. ${ }^{2}$ Notoriamente, é um evento que todos os seres humanos vivenciam, entretanto, o que varia são as formas de enfrentamento, pois são dependentes da formação cultural, religiosa e social. $^{3}$ Observa-se que 0 ato de morrer tornou-se solitário, desumano e mecânico. Perante o acometimento de uma patologia com algum grau de complexidade e gravidade, encaminha-se o indivíduo adoecido ao ambiente hospitalar. Isso, na maioria das vezes, é feito abruptamente e com rapidez pela família ou por profissionais de saúde de resgate e atendimento pré-hospitalar. Promove-se, com esse fato, um distanciamento físico e emocional entre o paciente e seus familiares, inclusive, sobre decisões relacionadas ao tratamento e ao processo de evolução do quadro clínico instalado, que deveriam ser conjuntas. ${ }^{4}$

Em parte, o morrer solitário no hospital talvez ocorra devido aos profissionais de saúde estarem cada vez mais qualificados para atuar com diferentes tecnologias de alta complexidade que prolongam a vida do paciente, sobretudo aquelas inseridas em unidades de emergência ou de cuidados intensivos. Percebe-se, porém, que muitos profissionais não estão, na mesma medida, preparados para lidar com o paciente e seus familiares diante do processo da morte e morrer. Por sua vez, torna-se difícil vivenciar a perda do paciente também para os profissionais de saúde. ${ }^{5}$

0 receio de enfrentar a morte pelos profissionais de Enfermagem pode trazer malefícios individuais e, também, ao ambiente de trabalho como um todo. Supostamente, estes profissionais estariam capacitados para lidar com o processo de morte dos pacientes, porém, a dificuldade de enfrentamento inicia-se na graduação, bem antes da prática profissional, visto que o tema morte e morrer, muitas vezes, é pouco abordado no decorrer das disciplinas teóricas e práticas. ${ }^{6-7}$

Nesse sentido, revela-se que o contexto cronológico do desenvolvimento humano (nascer, crescer, reproduzir, envelhecer e morrer) torna-se mais aceitável e natural aos profissionais de saúde quando pessoas idosas morrem. Aceita-se, com maior dificuldade, a morte de neonatos e crianças, pois esses seres pouco puderam conhecer, produzir e deixar marcas na família e na sociedade. Constituise, portanto, um grande desafio para os profissionais perder um paciente pediátrico ou jovem, especialmente frente a problemas agudos de saúde ou acidentes e causas externas, pois eles não sabem como lidar/trabalhar com esse tipo de adversidade. ${ }^{8}$

Sabe-se que, no contexto emergencial, o paciente e o salvamento de sua vida devem constituir o foco do atendimento, mas, por outro lado, faz-se necessário garantir que a equipe acolha os familiares angustiados e preste, ao mesmo tempo, uma assistência centrada na família e no paciente. ${ }^{9}$ Torna-se imperioso que os familiares, no serviço de emergência, sejam tratados como um paciente secundário, atentando-se às suas necessidades visto que, muitas vezes, chegam ao ambiente hospitalar ansiosos, agitados, angustiados e inseguros. Deve-se esclarecer suas dúvidas sobre a doença e seus medos acerca da possível morte do ente querido. ${ }^{3}$

De modo geral, ao conhecer as perspectivas dos profissionais de Enfermagem sobre o processo de morte e o morrer, torna-se possível direcionar atividades/intervenções que diminuam o sofrimento tanto desses profissionais que atuam nos setores emergenciais, como da família. Preparando-se melhor a equipe de saúde, possibilita-se a melhora da qualidade do serviço prestado e a vivência da perda do paciente de forma mais natural. Permite-se, assim, que dispensem o cuidado com ética, profissionalismo e de acordo com os princípios da humanização da assistência.

\section{OBJETIVO}

- Conhecer a perspectiva dos profissionais de Enfermagem, que atuam na sala de emergência, sobre o processo de morte e morrer.

\begin{tabular}{l}
\hline MÉTODO \\
\hline \hline Estudo qualitativo, descritivo e \\
exploratório, realizado com enfermeiros e \\
técnicos em Enfermagem que atuavam na sala \\
de emergência do pronto atendimento de um
\end{tabular}


Hospital Universitário Público localizado no Sul do Brasil.

Esse setor possui quatro leitos, porém, dependendo da necessidade, comporta até oito pacientes. Por turno de trabalho, atuam, no mesmo, um enfermeiro e um ou dois técnicos em Enfermagem, de acordo com o número de pacientes em atendimento.

Ao todo, 70 profissionais atuam no Pronto Atendimento/HUM e, embora mensalmente ocorra rodízio entre os profissionais dos diferentes setores dessa unidade (enfermaria de cuidados semi-intensivos, setor de medicação pós-consulta e enfermarias de internação), muitos deles não são escalados para trabalhar na sala de emergência devido às características peculiares desse setor.

Delimitou-se como critérios de inclusão dos participantes no estudo: atuar no serviço há mais três meses, ser formado há mais de um ano e ter vivenciado o óbito de, pelo menos, um paciente. Já como critério de exclusão definiu-se: estar afastado do serviço atestado/férias durante o período da coleta de dados.

Abordaram-se, nos diferentes turnos de trabalho, 28 profissionais que atendiam aos critérios de inclusão/exclusão, porém, por motivos diversos, 11 se recusaram a participar da pesquisa, de modo que 17 profissionais se tornaram informantes do estudo.

Coletaram-se os dados, no período de agosto a outubro de 2017, por meio de entrevistas semiestruturadas, individuais e gravadas em mídia digital após a autorização dos participantes.

Realizaram-se as entrevistas nas dependências da instituição, em local privativo, em dia e horário de escolha dos participantes, de modo a não interferir em suas atividades de trabalho. Elas tiveram duração média de 20 minutos e foram guiadas pelas seguintes questões norteadoras: Como é, para você, perder um paciente? Como você enfrenta o processo de morte e morrer?

Durante as entrevistas, utilizou-se um instrumento elaborado pela pesquisadora com base no objetivo do estudo e na literatura corrente sobre o tema. Primeiramente, entrou-se em contato com os profissionais que atendiam aos critérios de inclusão do estudo para verificar a disponibilidade e o interesse em participar do mesmo. Agendaram-se as entrevistas ou elas foram realizadas em seguida, quando houve disponibilidade para tal.

As transcrições das entrevistas foram feitas logo após o seu término ou tão logo quanto possível para que diminuísse a possibilidade de esquecimento e para que não ocorresse perda de detalhes observados durante as mesmas.

Em seguida, procedeu-se a organização do material, que foi lido diversas vezes, identificando-se trechos-chave que correspondiam ao objetivo do estudo. A análise temática consiste em descobrir os núcleos de sentido que compõem uma comunicação cuja presença ou frequência signifiquem algo para o objetivo analítico pretendido. ${ }^{10-1}$ Dessa análise, emergiram duas categorias: Sentimentos e percepções frente ao processo de morte e morrer e Alterações na percepção da morte em diferentes fases da vida.

Durante o desenvolvimento do estudo, seguiram-se os aspectos éticos disciplinados pela Resolução n. ${ }^{\circ} 466 / 12$ do Conselho Nacional de Saúde e suas complementares. 0 projeto foi aprovado pelo Comitê Permanente de Ética em Pesquisa com Seres Humanos da Universidade Estadual de Maringá (UEM) e registrado sob o CAAE 71053917.7.0000.0104. Todos os participantes assinaram o Termo de Consentimento Livre e Esclarecido em duas vias. Identificaram-se trechos de seus relatos com as siglas (ENF) para enfermeiro e (TE) para técnico em Enfermagem seguidas de um número indicativo da ordem de realização das entrevistas.

\section{RESULTADOS}

Fizeram parte do estudo 17 profissionais, dos quais dez eram técnicos em Enfermagem e sete, enfermeiros. A faixa etária encontrou-se entre os 22 aos 55 anos e a maioria era do sexo feminino (15). O tempo de atuação na área variou de três a 33 anos e sete deles possuíam pós-graduação/especialização em áreas diversas. Ressalta-se que, dos dez técnicos em Enfermagem, três possuíam graduação em Enfermagem, porém, exerciam atividades técnicas.

Da análise dos dados, emergiram duas categorias temáticas empíricas descritas a seguir.

\section{- Sentimentos e percepções frente ao processo de morte e morrer dos pacientes}

Apresentam-se, nesta categoria, os relatos das percepções e sentimentos dos profissionais de Enfermagem frente ao processo de morte e morrer, bem como o envolvimento dos mesmos durante a perda do paciente e a falta de formação/preparo para - enfrentamento da morte durante a graduação. 
Baldissera AE, Bellini LC, Ferrer ALM et al.

De modo específico, os depoimentos apontam a dificuldade que os profissionais têm de abordar o tema e lidar com a morte, especialmente, quando o paciente permanece por mais tempo na sala de emergência. Isto porque os profissionais passam a lidar não somente com o sujeito hospitalizado, em estado grave de saúde, mas também com sua família criando-se, muitas vezes, vínculos com os familiares.

Você cria um vínculo familiar, então, se o paciente fica muito tempo e você se apega à família, o sofrimento é ainda maior (...). (ENF3)

Você chora de ver a dor da família, aquele clamor da mãe de querer ver seu filho de volta. É complicado falar da morte, principalmente na emergência, você se sente incapaz. (TE4)

Falar de morte sempre vai ser uma coisa difícil porque é algo que ninguém trabalha bem (...). (ENF5)

Ao serem questionados sobre os principais sentimentos vivenciados frente ao processo de morte e morrer do paciente na Sala de Emergência, os profissionais identificaram que o sofrimento era a experiência mais comum e este era qualificado pelos sentimentos de tristeza, impotência e frustração frente à assistência prestada.

Dá tristeza, dá frustração (...) se tivesse sido melhor assistido, mas gera, sim, principalmente, bastante frustração, fico frustrada, pois foi feito de tudo, mas a pessoa morreu, às vezes, em um acidente, é isso, bem difícil. (TE2)

É uma sensação de constrangimento, que você poderia ter feito mais. (ENF3)

Os sujeitos relataram, em seus depoimentos, que, durante a formação profissional, não tiveram, da forma como esperavam ou acreditavam necessária, capacitação, nem tampouco suporte para enfrentar a morte de pacientes. Ressaltaram que, após ingressar no mercado de trabalho, a realidade foi muito distinta da vivenciada na parca teoria abordada sobre o tema e foi no local de trabalho onde tiveram a oportunidade de desenvolver habilidades para lidar com a situação e estratégias para enfrentar/apoiar a família do paciente que foi a óbito.

Não, não tive preparo, o que eu tive foi: "Vai, que você tem que encarar!". Eu me lembro muito bem da professora nos falando isso. Me fez muita falta durante a graduação porque não dá para fugir desse tema, uma hora vamos ter que encarar. (ENF7)

Não tive nenhum preparo. Quando eu fiz o curso técnico, sempre aprendemos a lidar com o salvar vidas e não com a morte. (TE5)
Perspectiva de profissionais de enfermagem...

Na faculdade, não se fala de morte, não se fala de perda, se fala apenas em querer ajudar, cuidar e curar. (ENF5)

Alguns profissionais acreditam que a experiência profissional promove mudanças na prática assistencial caracterizada por amadurecimento profissional e pessoal, impessoalidade e discernimento no trabalho com a situação da perda.

Identificou-se, durante as entrevistas, que esses profissionais concebem o trabalho na sala de emergência como desgastante e estressante, especialmente nos casos de pacientes sem possibilidades terapêuticas. Apoiam-se em estratégias diversas, em uma tentativa de afastar sentimentos negativos relacionados às situações frustrantes do dia de trabalho, para que esses sentimentos não afetem sua vida pessoal e, também, para que não interfiram nos cuidados aos demais pacientes.

Hoje, eu já enfrento diferente porque eu sei que minha técnica é bem desenvolvida, eu tenho um conhecimento bem amplo (...). (ENF1)

Você vai aprendendo a lidar com a situação (...) você passa a aceitar mais as coisas, a gente tem que ver o processo natural (...). (TE4)

Nós mantemos o olhar profissional, o dia a dia vai nos tornando mais preparados. Vendo que aquele paciente é uma vida, a gente mantém a postura ética, mas a gente sente (...). (ENF6)

Você tem que ter profissionalismo para não levar isso para o dia a dia, (...) não levar isso para fora, para você (...). A partir do momento que você vai embora, tem que desprender. (...) eu, como profissional, me envolvo muito, mas tenho que deixar isso aqui, não posso levar da porta para fora, senão você não vive, (...) ser profissional é fazer aquilo dentro de um hospital. A partir do momento que você encerra sua jornada de trabalho, você tem que esquecer e levar a sua vida adiante. (ENF2)

\section{- Alterações na percepção da morte em diferentes fases da vida}

Selecionaram-se, para ilustrar esta categoria, as falas que expressam as dificuldades sentidas por alguns profissionais para lidar com a morte de pessoas jovens ou crianças - especialmente vítimas de doenças agudas ou causas externas. Justifica-se essa dificuldade pelo simples fato de essa não ser a ordem cronológica da vida. Acredita-se que essas pessoas ainda teriam muitos sonhos a serem realizados e um futuro promissor, que é abruptamente interrompido pela morte. Alguns profissionais revelaram grande envolvimento emocional e vivência de 
Baldissera AE, Bellini LC, Ferrer ALM et al.

sentimentos como decepção e tristeza nesses casos.

É um ser pequeno e não viveu nada, acho que essa é a sensação, não era a hora de morrer, a gente acha que vamos morrer velhos e sabemos que não tem hora para morrermos. (ENF5)

Foi muito difícil para mim, tanto que eu nem gosto de trabalhar com crianças, não é que eu não goste de criança, eu sou muito carinhosa, eu gosto, eu sofro junto, eu choro junto com a família, eu acabo me envolvendo muito. É difícil de ver a mãe e a família desesperada. Eu com a criança temos dificuldade para trabalhar. Aqui, na emergência, eu faço, eu vou e faço o que tenho que fazer, eu sou profissional. (ENF6) Eu fiquei muito chateada (...). Ninguém está esperando a morte de uma criança, mesmo nós que somos profissionais da saúde, (...) é uma decepção, é complicado, eu fiquei muito chorosa (...). (ENF1)

Observou-se que a morte de pacientes mais idosos ou com doença terminal é mais facilmente aceita pelos profissionais, pois acreditam que esta constitui-se em percurso natural da vida. Posicionam-se de modo diverso diante da morte de um paciente jovem e a de um idoso, pois possuem a crença de que a pessoa idosa já passou por todas as fases, já teve sua história e deixou descendentes. Nesses casos, a morte constitui-se em um evento esperado.

Então, quando é um idoso, você quer confortar, você faz os cuidados, é um cuidado paliativo, é uma pessoa de 80, 100 anos, a família está sentida, sofrendo, mas, assim, ele já teve netos, bisnetos, ele já teve uma história. (TE4)

Um idoso já viveu, não que a gente não sinta, então, a gente consegue entender melhor. (ENF6)

\section{DISCUSSÃO}

Faz parte da rotina de trabalho dos profissionais de saúde, nomeadamente aqueles inseridos em ambientes de cuidados críticos e emergenciais, o processo de morte e morrer. Essa temática, no entanto, não é abordada facilmente nem mesmo por esses profissionais que, comumente, reagem de diferentes formas diante do evento.

Realizou-se um estudo nas Unidades de Terapia Intensiva (UTI) de dois hospitais em Patos-PB e observou-se, principalmente, a insegurança dos profissionais em discorrer diretamente sobre o assunto, sendo que muitos evitavam citar a palavra "morte", a qual era substituída por outras palavras como: término, passagem, certeza e acontecimento. Tal achado coaduna-se com os resultados desta pesquisa, em que se aponta que a
Perspectiva de profissionais de enfermagem...

resistência em debater a temática apresentase como um dos principais motivos para as dificuldades encontradas. ${ }^{1}$

Encontraram-se profissionais constrangidos diante do reconhecimento e enfrentamento da finitude do ser humano aflorando sensações de diversas naturezas. Detectaram-se, nas falas, sentimentos como impotência, tristeza, frustração e dor.

Realizou-se estudo em um hospital público da Zona da Mata de Minas Gerais, com dez profissionais da equipe de Enfermagem (enfermeiros, técnicos e auxiliares em Enfermagem), no qual mostrou-se que a morte se integra na rotina de trabalho desses profissionais. Nesse contexto, ressalta-se a fragilidade humana levando os profissionais a reconhecerem a própria finitude. A frustração é outro sentimento que se faz muito presente no cotidiano, pois, quando o paciente vai a óbito, quebra-se o vínculo entre pacienteenfermeiro. ${ }^{12}$

Percebe-se que ainda impera o entendimento de que os hospitais têm, como propósito, a cura das pessoas internadas e que a morte se apresenta como uma oposição a isso. Os profissionais de saúde se percebem com a missão de lidar com a vida e, quando presenciam a morte, têm a propensão a retratá-la como falha no fornecimento dos cuidados resultando em sentimentos de angústia, culpa, estresse e impotência frente à função de salvar vidas. ${ }^{13-4}$

A experiência profissional constitui-se em uma grande aliada para o enfrentamento à morte. Mostra-se relevante a segurança obtida pela execução exaustiva da prática assistencial dos múltiplos casos clínicos experienciados com finais variados.

Demonstra-se, em estudos, que os profissionais da área da saúde, em especial o enfermeiro, acreditam que vivenciar a morte e o morrer no cotidiano de trabalho é desafiador, porém, em muitos casos, conseguem reconhecer que esse é um processo natural da vida e que, inevitavelmente, todos, um dia, passarão por isso e que faz parte da realidade diária de trabalho. Procura-se criar estratégias para lidar com a morte com o mínimo de envolvimento emocional pois, mesmo não havendo uma reação terapêutica por parte do paciente, tem-se o sentimento de dever cumprido. ${ }^{12,15}$

Afirma-se que o convívio diário com o óbito de pacientes desencadeia sentimentos de pesar nos profissionais. Nesses casos, faz-se necessário ter um maior entendimento sobre esse acontecimento e controle das emoções. 
Desse modo, acredita-se ser possível oferecer suporte ao paciente em processo de finitude da vida e a seus familiares. ${ }^{15}$ Dessa maneira, torna-se necessário manter distância emocional daquilo que ocorre com frequência no seu meio de trabalho, sendo entendido como um mecanismo de defesa e proteção para a maioria dos profissionais. ${ }^{8}$

Ressalta-se que, na percepção dos profissionais em estudo, ao longo da graduação, aborda-se pouco o tema morte. ${ }^{16}$ Preparam-se os acadêmicos para cuidar, promover a vida e a cura. Conscientiza-se sobre o compromisso com a preservação da vida dos pacientes sob seus cuidados e, quando isso não ocorre, passa-se a perceber a morte como um imprevisto ou um fracasso em sua vida profissional. Portanto, no Brasil, trabalha-se pouco o tema morte nas matrizes curriculares e essa lacuna gera um despreparo no futuro do profissional. ${ }^{16-8}$

0 processo de morte e de morrer constituise um desafio para os discentes de Enfermagem diante do pouco preparo que os profissionais da área demonstram no enfrentamento da morte, comportamento responsável por potencializar os sentimentos de impotência e aversão gerados durante a graduação. Ao abordar o processo da morte e morrer nas salas de aula, nos laboratórios de práticas e, principalmente, nos campos de estágio, preparam-se os futuros profissionais para atender e intervir junto ao paciente hospitalizado e seus familiares. Enfim, contribui-se para o cuidado do enfermo com um olhar mais humano e vivenciando-se a situação com menos sofrimento profissional. ${ }^{19-}$ 20

Ao analisar a segunda categoria, constatase, em estudos realizados com profissionais de Enfermagem de UTI pediátrica da rede pública de saúde, que o processo de morte e morrer, na área da pediatria, desperta sentimentos de desconforto nos profissionais. Isso acontece porque eles criam laços afetivos com esses pacientes, o que torna visível a dificuldade de enfrentamento e intensifica a ideia de evento inaceitável para um ser que está começando a viver. $^{21-2}$

A morte e o morrer constituem aspectos inerentes à condição humana e parece que essa condição é mais sentida quando se estende à população infantil. Aceitar a morte de uma criança ou adolescente parece retirar a esperança colocando os profissionais diante do fim prematuro de uma existência. ${ }^{15}$

Acredita-se que alguns membros da equipe de Enfermagem acabam se envolvendo sentimentalmente, vivenciando sensações de incômodo, dor e sofrimento, ao prestar Português/Inglês

Rev enferm UFPE on line., Recife, 12(5):1317-24, maio., 2018 cuidados a pacientes pediátricos. Além disso, a morte de pacientes jovens contraria a expectativa de vida causando uma inversão da ordem cronológica. ${ }^{8,22}$

Identifica-se que muitos profissionais acreditam que a morte está interligada ao processo senil e que a pessoa idosa já passou por todas as fases do ciclo vital pressupondo, assim, que esses indivíduos já realizaram suas trajetórias na Terra. ${ }^{13}$

Sabe-se que a morte pode ocorrer em qualquer fase da vida, porém, aceita-se melhor e espera-se que ela seja mais frequente em pessoas idosas, sem 0 rompimento das diferentes fases pelas quais um ser humano naturalmente deveria passar. Entretanto, a morte não ocorre apenas na velhice até porque morrer constitui-se em uma possibilidade sempre presente. Desde o nascimento, somos suficientemente velhos para morrer, mas a morte é mais aceita e esperada na senilidade $e$, na melhor das hipóteses, fará sua chegada à idade avançada. $^{15}$

Afirma-se que a morte, em qualquer fase da vida, pode constituir-se em causa de sofrimento entre os profissionais, a depender das circunstâncias nas quais ocorre e da forma como se empregam mecanismos de defesa para enfrentá-la. Nesse sentido, estudo sobre os sentimentos de profissionais de Enfermagem em relação à morte de uma pessoa idosa internada identificou a presença de sofrimento pelo fato de eles vivenciarem questões intrínsecas à profissão como o término da vida ou o abandono do idoso pela família. ${ }^{23}$

Ante o exposto, acredita-se que os achados desta investigação podem impactar a prática clínica e o ensino. Aponta-se que atividades educativas para o enfrentamento da morte nos serviços de saúde, especialmente naqueles que ofertam cuidados críticos e emergenciais a pacientes nos diferentes ciclos da vida, constituem-se em estratégias necessárias a serem empregadas pelos serviços de educação continuada das unidades, assim como pelas universidades/faculdades. Possibilita-se, assim, que os profissionais se sintam, de alguma forma, mais bem preparados para o enfrentamento cotidiano do processo de morte e morrer junto ao paciente em finitude da vida e sua família.

Destaca-se que esta investigação possui limitações. Muitos profissionais, apesar de oportunizar que a entrevista fosse realizada em outro local, não aceitaram que ocorresse fora do ambiente de trabalho. Possibilitou-se, com isso, a participação de um número maior 
de profissionais, mas, ao mesmo tempo, configurou-se como limitação, pois, embora outro colega tenha ficado no setor, os demais se preocupavam com a possibilidade de algum paciente dar entrada no setor durante a entrevista, o que fez com que as mesmas fossem breves. Além disso, acrescenta-se que este estudo ocorreu apenas em uma unidade de emergência e seus achados, portanto, limitam-se à população investigada necessitando-se cautela na comparação com resultados de outros estudos.

\section{CONCLUSÃO}

Conclui-se que, na perspectiva dos profissionais que atuam na sala de emergência, a morte faz parte do processo de viver, é uma ocorrência relativamente comum nesse setor e, ainda assim, constitui-se em evento gerador de sentimentos negativos. Apontam-se como influentes nessa perspectiva: experiências anteriores nos âmbitos pessoal e profissional; a condição clínica e a idade do paciente e o tempo de permanência/convivência com o paciente e sua família.

Considera-se que os resultados deste estudo contribuirão para o avanço do conhecimento na medida em que mostram a deficiência da abordagem da temática em estudo na formação dos profissionais de nível técnico e superior e, ainda, quando explicitam os fatores que influenciam suas perspectivas sobre o processo de morte e morrer, bem como as estratégias utilizadas para enfrentar essa questão no cotidiano de trabalho.

Acredita-se que os resultados do estudo possam contribuir para que a equipe de Enfermagem que atua na sala de emergência sinta-se mais motivada para refletir e discutir, em seu ambiente de trabalho, sobre a morte e o morrer e mecanismos de enfrentamento refletindo em cuidados mais humanos e solidários ao se deparar com a morte de pacientes em qualquer faixa etária.

\section{REFERÊNCIAS}

1. Lacerda CA, Camboim FEF, Camboim JCA, Nunes EM, Bezerra ALD, Sousa MNA. O lidar com a morte em unidade de terapia intensiva: dificuldades relatadas por enfermeiros. Rev Eletr Fainor [Internet]. 2016 Dec [cited 2017 Oct 14];9(2):173-84. Available from: http://srv02.fainor.com.br/revista/index.php /memorias/article/view/559/294

2. Oliveira FA, Ferreira PS, Carneiro TRQS, Souza SR. The feelings and behaviors of the nursing team before the death of the patient. Vita Et Sanitas [Internet]. 2012 Dec [cited 2017 Nov 13];5(6):104-22. Available from:
http://www.fug.edu.br/revista/index.php/Vit aetSanitas/article/view/54/46

3. Ferreira PD, Mendes TN. Family in ICU: Importance of Psychological Support Given the imminence of death. Rev SBPH [Internet]. 2013 June [cited 2017 Oct 11];16(1):1-25. Available from: http://pepsic.bvsalud.org/pdf/rsbph/v16n1/v 16n1a06.pdf

4. Kübler-Ross, E. Sobre a morte e o morrer. 4th ed. São Paulo: Martins Fontes; 2016.

5. Kuster DK, Bisogno SBC. Perceptions of nurses on the patient's death. Discip Sci Ser Cienc Saude [Internet]. 2010 [cited 2017 Oct 10];11(1):9-24. Available from: https: / / www.periodicos.unifra.br/index.php/ disciplinarumS/article/view/961/904

6. Ferreira APA, Sabatke CE, Montezeli JH, Venturi KK. Experience the death of victims of trauma in ready-salvage descriptive study. Online Braz J Nurs [Internet]. 2012 May [cited 2017 Oct 11];11(1):137-47. Doi: http://dx.doi.org/10.5935/16764285.20120013

7. Wondracek L, Rosanelli CLSP, Piovesan SMS. What helps the team? Strategies for coping with the death of patients in ICU. Rev Contexto Saude. 2011 June;10(20):327-34. Doi: $\quad$ http://dx.doi.org/10.21527/21767114.2011.20.327-334

8. Zheng RS, Guo QH, Dong FQ, Owens EG. Chinese oncology nurses experience on caring for dying patients who are on their final days: a qualitative study. Int J Nurs Stud. 2015;52(1):288-96.

Doi:

https://doi.org/10.1016/j.ijnurstu.2014.09.00 $\underline{9}$

9. Barreto MS, Arruda GO, Garcia-Vivar C, Marcon SS. Family centered care in emergency departments: perception of brazilian nurses and doctors. Esc Anna Nery Rev Enferm. 2017 Nov;21(2):e20170042.

Doi:

http://dx.doi.org/10.5935/1414-

\subsection{2}

10. Minayo MCS. Pesquisa social: teoria, método e criatividade. 29th ed. Petrópolis: Vozes; 2010.

11. Minayo MCS. O desafio do conhecimento: pesquisa qualitativa em saúde. São Paulo: Hucitec; 2014.

12. Salimena AMO, Ferreira GC, Melo MCSC, Souza IE. Meaning of death of the surgical patient experienced by the nursing team. Rev Enferm UFSM. 2014 Sept;4(3):645-51. Doi: http://dx.doi.org/10.5902/2179769211267

13. Both JE, Leite MT, Hildebrand LM, Spies J, Silva LAA, Beuter M. The dying and death of elderly hospitalized in perspective of nursing professionals. Ciênc Cuid Saúde. 2013 
Baldissera AE, Bellini LC, Ferrer ALM et al.

Sept;3(12):558-65.

Doi:

http://dx.doi.org/10.4025/cienccuidsaude.v1 2i3.18302

14. Barros RNS, Oliveira SC, Gonçalves LC, Santos EC, Costa AWS, Azevedo AP, et al. Perceptions of the nursing team to the patient outside therapeutic possibilities. Rev Uninga [Internet]. 2017 Dec [cited 2017 Dec 4];32(1):137-46. Available from: http://revista.uninga.br/index.php/uningarev iews/article/view/62/433

15. Lima RS, Costa Júnior JA. The process of death and dying in nurses vision. ReOnFacema [Internet]. 2015 Oct [cited 2017 Nov 5];1(1):25-30. Available from: http://www.facema.edu.br/ojs/index.php/Re OnFacema/article/view/13/8

16. Ivo OP, Pedroso KO. The process of death and dying: a vision of nursing students. Id Online Rev Psic. 2017 Feb;11(34):305-21. Doi: https://doi.org/10.14295/idonline.v11i34.691 17. Borges MC, Gomes BLBD. Perceptions of nursing students regarding the terminal process of life. Rev Enferm Contemporânea. $2017 \quad$ Apr;6(1):49-55.

http://dx.doi.org/10.17267/2317-

3378rec.v6i1.1183

18. Zheng RS, Lee SF, Bloomer MJ. How new graduate nurses experience patient death: A systematic review and qualitative metasynthesis. Int J Nurs Stud. 2016 Jan;53:320-30.

Doi:

http://dx.doi.org/10.1016/j.ijnurstu.2015.09. $\underline{013}$

19. Bastos R, Lamb F, Quintana A, Beck C, Carnevale $F$. The experiences of nurses in the dying process: a qualitative meta-synthesis. Rev port enferm saúde mental. 2017 June;17:58-64.

Doi:

http://dx.doi.org/10.19131/rpesm.0184

20. Nunes ECDA, Santos AA. Challenges of nursing teaching-learning to care for human dying - professors' perceptions. Esc Anna Nery Rev Enferm. 2017;21(4):e20170091. Doi: http://dx.doi.org/10.1590/2177-9465-EAN2017-0091

21. Scarton J, Poli G, Kolankiewicz ACB, Rosanelli CLSP, Scarton J, Poli AG. Nursing: death and dying in a pediatric and neonatal intensive care unit. J Nurs UFPE on line. 2013 Oct;10(7):5929-37.

Doi: http://dx.doi.org/10.5205/reuol.4377-366191-ED.0710201321

22. Lima BSF, Silva RCL. Death and dying in a pediatric icu: challenges for nursing care in the finitude of life. Cienc Cuid Saúde. 2014 Dec;13(4):722-9.

Doi:

http://dx.doi.org/10.4025/cienccuidsaude.v1 $3 \mathrm{i} 4.21530$
Perspectiva de profissionais de enfermagem...

23. Silva RS, Campos AER, Pereira A. Caring for the patient in the process of dying at the intensive care unit. Rev Esc Enferm USP. 2011 July;45(3):738-44. Doi: http://dx.doi.org/10.1590/S0080$\underline{62342011000300027}$

Submissão: 16/01/2018

Aceito: 11/02/2018

Publicado: 01/05/2018

Correspondência

Luana Cristina Bellini

Rua Sueo Toda, 163, Ap. 104

Bairro Vila Esperança

CEP: 87020410 - Maringá (PR), Brasil 